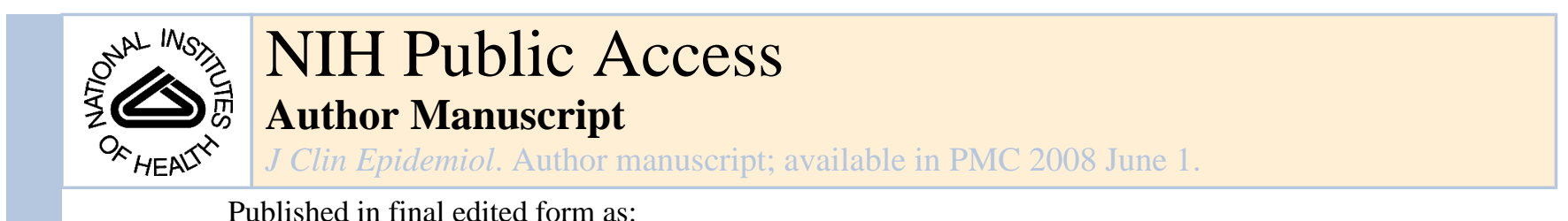

Published in final edited form as:

J Clin Epidemiol. 2007 June ; 60(6): 593-594.

\title{
Letter to the Editor:
}

\section{Ethnic Differences in Medical Procedure Decisions}

\section{Carmen Curtis, Ph.D.}

December 11, 2006

Dear Editor:

In the October 2006 issue, Byrne et al. reported that African American adults are less likely than Caucasians or Latinos to choose total knee replacement surgery (TKR) to treat osteoarthritis (OA) when presented with various medical scenarios [1]. Because TKR can greatly improve patients' quality of life, the authors should be commended for addressing factors that may inhibit patients, particularly ethnic minorities, from opting to have the surgery. The finding that different factors influenced decisions regarding surgery for various racial groups can provide important information for health care providers in tailoring their interventions. The authors also demonstrated that conjoint analysis, a methodological approach most frequently utilized for marketing research, may be innovative for studying preferences in health care. However, I do have a few concerns regarding their methodology and conclusions.

As the authors pointed out, persons who suffer from OA could have different preferences than persons who do not have OA when presented with hypothetical scenarios regarding treatment options. Yet in order to compare persons from the general public to actual patients, the authors utilized different selection criteria in terms of age. Older adults may have different health care preferences than younger adults simply based on their age, making it difficult to attribute differences between the public and patient samples to OA status. Consequently, this may have introduced bias that weakens the generalizeability of the findings to the larger population.

Moreover, the study did not appear to use theoretical grounding when selecting variables to investigate, which limited its ability to adequately address confounding factors. For example, the authors failed to assess variables from the widely used Health Belief Model [2], which suggests that beliefs about individual vulnerability to disease, confidence in treatment efficacy, and perceived barriers to care influence health behaviors and decisions. Education, which may affect the understanding of medical procedures, was also overlooked as a factor in deciding whether to choose TKR. As other studies state, familiarity with the TKR procedure could also be associated with increased or decreased TKR use [3], but the present study did not explicitly assess this. To their credit, the researchers did admit that their variables accounted for a relatively low percentage of statistical variance.

Furthermore, even though African Americans chose surgery less frequently than Caucasians in the hypothetical scenarios, is it appropriate to conclude that racial disparities in surgery are

Corresponding Author: Carmen Curtis, PhD, NIMH Postdoctoral Research Scholar, Washington University School of Medicine, Department of Psychiatry, Campus Box 8134, St Louis, MO 63110, Phone: 314-362-5426, Fax: 314-286-2265, E-mail: curtisc@psychiatry.wustl.edu

Publisher's Disclaimer: This is a PDF file of an unedited manuscript that has been accepted for publication. As a service to our customers we are providing this early version of the manuscript. The manuscript will undergo copyediting, typesetting, and review of the resulting proof before it is published in its final citable form. Please note that during the production process errors may be discovered which could affect the content, and all legal disclaimers that apply to the journal pertain. 
due to personal preferences? After all, societal factors such as socioeconomic status, distrust of the medical field, and racial discrimination continue to create inequities in access to health care. If African Americans truly are reluctant to undergo a potentially helpful surgery such as TKR, this may have little to do with personal preference and more to do with what are perceived to be the risks and benefits associated with available options. Focusing too heavily on personal choices with regards to accessing health care can overshadow the responsibilities of the greater community in ensuring that historically disadvantaged populations receive adequate medical attention. Therefore, considering the implications of these findings for the African American population, the conclusions drawn from this study must be used with caution.

In sum, while I believe the authors have made an excellent start in delving into the differences in preference for elective surgery across racial/ethnic groups, I feel that more comprehensive research is needed to truly understand what personal preferences may be influencing these health decisions. I also look forward to continued research looking more closely at societal and cultural factors that could be underlying health care choices.

Thank you for your consideration,

Carmen Curtis, Ph.D.

NIMH Postdoctoral Research Scholar

Washington University School of Medicine

Department of Psychiatry

\section{References}

1. Byrne MM, Souchek J, Richardson M, Suarez-Almazor M. Racial/ethnic differences in preferences for total knee replacement surgery. Journal of Clinical Epidemiology 2006;59(10):1078-86. [PubMed: 16980148]

2. Rosenstock IM. Historical origins of the Health Belief Model. Health Education Monogram 1974;2:328-35.

3. Whittle J, Conigliaro J, Good CB, Joswiak M. Do patient preferences contribute to racial differences in cardiovascular procedure use? Journal of General Internal Medicine 1997;12(5):267-273. [PubMed: 9159695] 